\title{
Economias de Escala e de Escopo: Desmistificando alguns Aspectos da Transição
}

\section{Cláudio Szwarcfiter}

Doutorando do DEI/PUC-Rio

\section{Paulo Roberto T. Dalcol}

Professor Associado, $\mathrm{PhD}$

Departamento de Engenharia Industrial, PUC-Rio. Rua Marquês de S. Vicente, 225, Gávea, Rio de Janeiro, RJ. E-mail prtd@rdc.puc-rio.br

Palavras-chave: economias de escala, economias de escopo, mudança técnica. Keywords: economies of scale, economies of scope, technical change.

\section{RESUMO}

Nas duas últimas décadas, o mundo industrial assistiu a uma crescente fragmentação e segmentação dos seus mercados, especialmente para o setor de bens de consumo duráveis. $O$ resultado consiste na crescente dificuldade para a exploração das economias de escala 'tradicionais' por meio de equipamento altamente especializado e a produção de bens padronizados. Dai a recente ênfase no conceito de economias de escopo. Entretanto, várias conclusões imprecisas são encontradas na literatura referentes à transição de economias de escala para economias de escopo. $O$ propósito deste artigo é identificar algumas dessas conclusões e introduzir argumentos no sentido e organizar a discussão sobre o assunto.

\footnotetext{
ABSTRACT

In the last two decades, the industrial world witnessed an intensifying fragmentation and segmentation of its markets, especially for the consumer durable goods. The upshot is the ever-increasing difficulty for the exploration of 'traditional' economies of scale by means of highly specialised equipment and production of standardised goods. Thus, the recent vogue of the concept of economies of scope. Nevertheless, various inaccurate conclusions in relation to the transition from economies of scale to economies of scope are found in the literature. The aim of this paper is to pinpoint some of these conclusions and try to introduce some arguments in order to organise the discussion on the subject.
} 


\section{PRODUÇĀO}

\section{Introdução}

Nos últimos tempos, verifica-se uma crescente tendência à segmentação dos mercados consumidores, afastando-se cada vez mais dos tradicionais mercados de produtos padronizados, inerentes ao paradigma industrial baseado na produção em massa. $O$ resultado mais importante do fenômeno consiste na crescente dificuldade de as firmas se organizarem nos moldes do Fordismo, com a exploração de economias de escala por meio de equipamentos rígidos que produzem bens estandardizados em grandes lotes para diluir, no custo unitário dos produtos, o alto investimento realizado nesses equipamentos.

Assim, torna-se patente a necessidade de mudanças fundamentais na organização da produção. Apesar de ser possivel, até mesmo através de simples observação empírica, apontar várias novas características nos sistemas produtivos hoje, vale lembrar que a atual fase pela qual passam esses sistemas ainda caracteriza-se como uma transição de paradigmas e, por isso, a identificação das características como sendo realmente e de fato integrantes do novo paradigma consiste em ato de mera especulação, desprovido de cientificidade.

Apesar disso, existe um fio sólido que costura toda a presente fase de grandes mudanças na organização industrial: a transição das economias de escala para as economias de escopo. Em outras palavras, as firmas que outrora produziam bens estandardizados por meio de equipamentos rígidos e dedicados, auferindo economias de escala, hoje procuram produzir bens com variedade crescente por meio de equipamentos flexiveis, explorando economias de escopo, transição esta possibilitada pelo advento das novas tecnologias de base microeletrônica.

No entanto, a literatura freqüentemente apresenta essa transição de uma forma confusa que conduz a conclusões errôneas. Talvez a principal conclusão equivocada seja a de que a possibilidade de produzir em lotes menores, aberta pela exploração de economias de escopo, implica na possibilidade de exploração dessas economias por pequenas firmas, acabando assim com as vantagens que as grandes firmas possuíam na era das economias de escala. Ou seja, escala seria um assunto para as grandes firmas e escopo, para as pequenas firmas.

Um dos objetivos deste artigo é mostrar que esta conclusão é falsa: tanto economias de escala quanto economias de escopo se referem a grandes firmas, isto é, firmas com uma escala minima de produção que possibilite a exploração dessas economias. Para tal, será realizada uma breve exposição dos conceitos de economias de escala e economias de escopo e, em seguida, serão tecidos alguns comentários relevantes para a melhor compreensão do fenômeno da transição. 


\section{Economias de Escala: Definições e Fatores Determinantes}

"Diz-se que há economias de escala quando o aumento do volume da produção de um bem por período reduz os seus custos. Esta redução pode se dar pela possibilidade de utilização de métodos produtivos mais automatizados ou mais avançados, mas também pode estar relacionada a ganhos em propaganda, marketing, $P \& D$, financiamento, enfim qualquer etapa da produção e comercialização. Até recentemente a ocorrência de economias de escala de grande porte era em geral associada à produção, por meio de processos contínuos, de insumos de uso generalizado, para os quais não cabe diferenciação de produto" (POSSAS, 1993, pp. 70-71).

As economias de escala subdividemse em duas categorias básicas: economias internas e economias externas. As economias internas "são aquelas que são abertas a uma única fábrica ou única firma independentemente da ação de outras firmas. Resultam de um aumento na escala de produção da firma, e não podem ser obtidas a não ser que a produção aumente" (CAIRNCROSS, 1973, p. 102). Por outro lado, as economias externas são aquelas em que um número de firmas ou indústrias tomam parte "quando a escala de produção em uma indústria ou grupo de indústrias aumenta." (ibid., p. 103) Estas economias "não são monopolizadas por uma única firma quando a mesma cresce em tamanho, mas são conferidas a esta quando algumas outras firmas crescem." (Ibid.)

Alguns autores argumentam que não existe uma clara distinção entre economias internas e externas. Economias externas em um dado momento podem ser consideradas economias internas em outro. Outros autores sequer abordam a questão das economias externas, amalgamando-as com as economias internas. Além disso, existem autores que definem os fatores determinantes das economias de escala em função de parâmetros como por exemplo tempo (curto, médio e longo prazo). De qualquer forma, a Figura 1 resume os fatores determinantes ou as subdivisões de cada tipo de economia de escala, do ponto de vista dos autores de economia em geral.

Considerando-se um enfoque mais pertinente à engenharia é interessante analisar as economias de escala de acordo com as razões que levam ao decréscimo dos custos unitários quando a produção é aumentada: os custos fixos são diluidos entre mais unidades, os custos e despesas de construção são reduzidos, os custos na compra de materiais e serviços podem ser cortados e, além disso, melhorias e cortes de custos no processo produtivo podem ser obtidos (KRAJEWSKI e RITZMAN, 1996).

É exatamente no último item acima que a Engenharia de Produção tem se mostrado particularmente importante. Altos volumes de produção apresentam 


\section{PRODUÇÃO}

oportunidades para a redução de custos e obtenção de benefícios através do aumento da velocidade do efeito da "curva de experiência", políticas de estoque mais adequadas, racionalização dos processos e melhoria de projetos de trabalho, simplificação de fluxos, etc.

Sem pretender aprofundar essa discussão, é interessante observar o que é considerado dentro das chamadas Economias de Especialização. A divisão do trabalho e a conseqüente especialização constitui talvez $o$ alicerce mais importante das economias de escala na produção em massa e, mais ainda, segundo muitos economistas políticos e sociólogos, uma das mais importantes características da produção industrial no modo de produção capitalista.
SCHERER (1980) faz uma interessante observação a respeito das economias de especialização, identificando o conceito com o processo de aprendizagem do learning by doing. Neste processo, os trabalhadores adquirem mais proficiência nas suas tarefas com 0 acúmulo de experiência; verifica-se oaumento da produtividade por trabalhador, a diminuição do número de erros cometidos e um declínio dos custos unitários ao longo da chamada curva de aprendizado. $\mathrm{O}$ autor exemplifica $\mathrm{o}$ conceito com a indústria de aviação militar norte americana durante a segunda Guerra Mundial, onde se observou uma redução de 20 por cento nos custos unitários de mão-de-obra cada vez que dobrava a produção acumulada.
Tipo de economia de escala

Economias externas

Economias internas
Fatores determinantes

$$
\begin{aligned}
& \text { Economias de concentração } \\
& \text { Economias de informação } \\
& \text { Economias de desintegração }
\end{aligned}
$$

Indivisibilidades

Especialização

Economias de grandes dimensōes

Economias de recursos em grandes quantidades

Economias financeiras

Economias de processos interligados

Economias de menor exposição aos riscos 
Obviamente que, pela própria forma da curva de aprendizado, sua importância é maior nos estágios iniciais do ciclo de vida do produto. A medida que o produto entra na sua fase de maturidade e 0 número acumulado de unidades produzidas se torna grande, os retornos do efeito do aprendizado diminuem.

A especialização também pode se dar a nivel de equipamentos, uma vez que a análise do processo de trabalho permite a invenção de equipamentos adequados para cada tarefa. Os equipamentos de uso mais geral são substituidos por equipamentos especializados projetados para executar operações especificas, com conseqüente aumento na produtividade. Vale lembrar que isso só é possível com o aumento de escala.

As grandes firmas normalmente são menos expostas ao risco devido à sua capacidade de agrupá-los: "Quanto maior o número de instâncias, menor o risco de erro no julgamento. Em um grande negócio, logo, onde a mesma operação é mais freqüentemente repetida do que em um pequeno negócio, a incerteza pode ser reduzida". (CAIRNCROSS, 1973, p. 114)

O agrupamento de riscos é extremamente importante em instituições financeiras. Um grande banco ou companhia de seguros tende a ser mais estável do que os seus equivalentes de porte menor, uma vez que é menos suscetível a qualquer instabilidade local. O agrupamento de riscos de natureza semelhante permite a aplicação da 'lei das médias', reduzindo-se assim as incertezas. Este processo pode ocorrer através de quatro formas básicas:

- Diversificação de mercados: para uma firma que fabrica determinado produto, o risco de flutuações na demanda pode ser reduzido através da comercialização do mesmo em diversos mercados, por exemplo de um mercado local para o nivel nacional ou global.

- Diversificação de fontes de suprimento: as grandes plantas normalmente têm mais condições de manter a produção quando uma determinada fonte de suprimentos é cortada por um motivo qualquer. Por exemplo, duas fontes de energia podem ser utilizadas (e.g. vapor e eletricidade), ou os suprimentos de matérias-primas podem ser adquiridos de uma área geográfica mais ampla, reduzindo-se a possibilidade de um corte total de determinado suprimento.

- Diversificação de processos de manufatura: analogamente à diversificação de fontes de suprimentos, uma grande firma tem maiores possibilidades de continuar a manter o processo produtivo em operação quando um determinado processo de manufatura torna-se não-econômico ou até mesmo impossivel.

- Diversificação da produção: se existe uma probabilidade razoável de uma firma ser afetada por um declínio na demanda para o seu produto, a mesma 
provavelmente procurará fabricar outros produtos que guardam certas semelhanças com este, de modo que possam ser fabricados simultaneamente. Poderá, assim, compensar um declínio nas vendas de um produto com um aumento nas vendas de outro, ou até mesmo se houver interrupção na fabricação de um produto, os outros continuarão a ser fabricados.

É principalmente neste ponto que se pode verificar a mola propulsora da transição das economias de escala para as de escopo nos setores da economia que sempre procuraram obter economias de escala através da padronização.

Com a fragmentação e constante mutação dos mercados, ficou patente a necessidade de diversificação aliada à flexibilização. Acontece que a mudança de produto nas linhas de fabricação e montagem rigidas tradicionais implica em custos muito altos (além de tempos muito longos). O problema, portanto, consiste na conciliação da necessidade de diversificação e flexibilização com a manutenção das vantagens disponiveis com as economias de escala.

É neste cenário que entra o conceito de economias de escopo, que será a seguir discutido - levando-se em conta o atual contexto de desenvolvimento vertiginoso da tecnologia de base microeletrônica como uma espécie de atualização das economias de escala: uma versão das economias de escala com a presença dessas novas tecnologias.
Antes porém, é oportuno registrar, como fizeram HAYES e WHEELWRIGHT (1984), que as economias de escala têm limite. Ou seja, aumentar a escala de produção permite à empresa reduzir uma série de custos, mas a partir de um certo ponto pode ocorrer o aumento de outros custos. Isto implicaria nas chamadas "Deseconomias de Escala" oriundas principalmente do aumento dos custos de distribuição, maior complexidade e confusão em função do número de niveis gerenciais e burocracias e até perda de foco. De qualquer forma, as deseconomias de escalas são consideradas como resultados de fatores que bons gerentes e/ou Engenheiros de Produção deveriam saber eliminar.

\section{Economias de Escopo: Um Velho Conceito Com Novas Dimensões}

Segundo PINDYCK e RUBINFELD (1992, p. 222), "economias de escopo estão presentes quando a produção conjunta de uma única firma é maior do que a produção que poderia ser obtida por duas firmas diferentes cada uma produzindo um único produto".

É importantíssimo salientar que as economias de escopo não constituem um novo conceito. CHANDLER (1990) aborda a questão da evolução da indústria através de uma perspectiva histórica $e$, ao se referir às principais inovações no processo de produção a partir do último 


\section{PRODUÇÃO}

quarto do século XIX, observa que os processos diferiam dos predecessores "no seu potencial para explorar as vantagens sem precedentes das economias de escala e escopo." (p. 21). Por exemplo, ainda no século XIX algumas fábricas alemãs de pigmentos já estavam realizando grandes investimentos para explorar plenamente as economias de escopo. As plantas expandidas produziam centenas de pigmentos e alguns fármacos a partir de um mesmo conjunto de matériasprimas e o mesmo grupo de componentes intermediários.

Verifica-se assim que o conceito de economias de escopo não é novo. Qual é, então, a grande diferença entre a operacionalização do conceito naqueles tempos e nos dias de hoje? A resposta está na natureza das inovações tecnológicas. $O$ novo fator-chave baseado na microeletrônica permite a exploração de economias de escopo em setores onde isso antes era impensável, com destaque para os bens de consumo duráveis - liderados pela indústria automobilística. Outrossim, torna-se mais fácil e barato o controle de qualidade com a crescente automação, assim como a coordenação do fluxo de produção. Nesses setores a necessidade de padronização, devido aos altos custos de 'set-up' e 'changeover', impossibilitava a produção com variedade e uma renovação mais rápida da linha de produtos.

Cabe salientar aqui, entretanto, que a redução dos tempos de ' set-up' e 'changeover' não se dá apenas pela introdução de novos equipamentos mais flexíveis, mas também através de técnicas de Troca Rápida de Ferramentas (TRF). De fato, mudanças para flexibilizar o sistema produtivo no sentido da produção de lotes menores já vinham sendo perseguidas desde a década de 50 por Shigeo Shingo com seus sistemas TRF e OTED (One-Touch Exchange of Die), os quais acabaram compondo um dos aspectos essenciais do Sistema Toyota de Produção (SHINGO, 1996).

Sem aprofundar a análise, sabe-se que longos tempos de set-up sempre foram um obstáculo à flexibilidade e, portanto, reduzi-los é de fundamental importância. Durante vários anos de aplicação prática, oito técnicas ou princípios básicos de troca de ferramenta e matrizes foram desenvolvidos. Destes, os seguintes, de acordo com o próprio autor, são os mais efetivos:

Distinguir claramente set-up interno (só pode ser realizado com a máquina parada) de set-up externo (pode ser conduzido com a máquina funcionando) externo

Converter set-up interno em

- Desenvolver grampos funcionais (fixadores sem rosca)

- Eliminar ajustes.

Desta forma, cria-se no chão-defábrica uma mentalidade de melhoria contínua e uma cultura de apoio a atividades de racionalização, fundamentais para a gerência dos sistemas produtivos. 
Mas é a produção flexível, através do corte radical nos custos de set-up e changeover com novas tecnologias, que permite produzir com mais variedade $\mathrm{e}$ flexibilidade, sem deixar, porém, de explorar as economias de escala; isto é, permite a exploração de economias de escopo.

Além disso, as economias de escopo podem advir da possibilidade de compartilhamento de uma série de inputs. Em outras palavras, as economias de escopo aparecem quando a restrição da especialização no uso de bens de capital é removida. Conclui-se que variedade e eficiência não são mais conceitos antagônicos. Os custos de produção conjunta compartilhando-se os inputs são mais baixos do que a soma dos custos de produção especificos: economias de escala com produções específicas são menores do que economias de escopo.

Com isto, tem-se a viablilidade econômica dos sistemas intensivos em informação. As economias de escala continuam existindo com a produção agregada. Entretanto, se a capacidade plena não é obtida para um determinado mix de produtos e um dado conjunto de equipamentos, a lacuna pode ser preenchida por meio da adição de um novo produto ao mix. Desta forma, se as economias de escopo resultantes forem significativas, compensarão, pelo menos até certo ponto, os custos adicionais de atividades relacionadas com, por exemplo, a coleta de informação.

\section{Observações Sobre a Transição}

Cabe agora detalhar mais alguns aspectos sobre a transição das economias de escala para as de escopo para esclarecer melhor alguns conceitos e desmistificar outros, que muitas vezes são apresentados na literatura conduzindo à conclusões errôneas.

Quando analisa-se o impacto dos equipamentos de produção flexivel na organização da produção, observa-se a redução dos tempos e custos de 'set-up' e 'changeover' - e a conseqüente possibilidade de produção em lotes menores - resultando na exploração de economias de escopo. ALCORTA (1994) apresenta o resultado de uma série de estudos realizados em empresas atuando nos setores de vestuário, impressão gráfica, válvulas e equipamentos industriais, equipamentos para encadernação, válvulas hidráulicas e caixas de câmbio, bicicletas e inđústria automobilística, comprovando os cortes nos tempos e custos citados e a redução da escala de produção de cada produto. As taxas de utilização dos equipamentos crescem devido à redução dos tempos de 'set-up', possibilidade de funcionamento durante um certo tempo sem operadores e menor número de panes.

No entanto, o autor adverte que é comum um exagero nas idéias a respeito da flexibilidade dos novos equipamentos. Por exemplo, na Ford entre 1914 e 1973 
o número de modelos oferecidos aumentou de 2 para 12 . No entanto, considerando somente o chassis básico dos veículos, o aumento foi de apenas 2 para 5. Assim, os novos modelos oferecidos correspondem mais a mudanças no estilo, especificações e cores do que novos produtos. Verificam-se assim, segundo o autor, dois pontos importantes: primeiramente, a dificuldade de se distinguir um produto de fato diferente de uma mera modificação de um produto mais antigo. Em segundo lugar, a existência - até hoje - de límites econômicos à flexibilidade, que em setores como metal-mecânica e indústria automobilística se fazem particularmente sentir. Ao que parece, o número de modelos oferecidos por algumas fábricas de automóveis japonesas ao invés de aumentar nos últimos anos, ao contrário, diminuiu.

Quando desloca-se a análise a nível de produtos para o nivel da planta, chegase a resultados mais importantes, que evidenciam a confusão que se faz entre as economias de escopo a nivel de produtos e a nivel da planta como um todo.

A implementação das novas tecnologias estaria facilitada pela queda nos custos de microprocessadores $e$ conseqüentemente dos bens de capital, além da redução do seu tamanho. Como consequêencia, estaria possibilitada ao extremo a operação de plantas menores. Outrossim, a padronização de equipamentos $\mathrm{CNC}$ e robôs estaria facilitando ainda mais a queda nos seus preços. Por fim, a modularidade das novas tecnologias permitiria a expansão da produção pela simples adição de pequenas partes, formando um sistema expansivel. Levantamentos realizados em vários setores da Europa e Japão concluiram, com base em indicadores de mão-de-obra, que de fato o tamanho médio das firmas está diminuindo, com o concomitante aumento da proporção de pequenas firmas nas indústrias.

ALCORTA (1994), no entanto, adverte para esses erros de interpretação. A confusão está entre os conceitos de tamanhos físico e econômico de uma planta e seu equipamento. Apesar da crescente miniaturização dos equipamentos de base microeletrônica, não se verifica uma queda na capacidade destes. Pelo contrário, devido à rapidez e eficiência destes equipamentos, além dos cortes nos tempos de 'set-up', pode ocorrer um aumento da capacidade da planta, $o$ que se passou a chamar de compactação.

Este fato passa de possibilidade para necessidade quando se examina os custos destes novos equipamentos, que continuam mais altos do que os dos 'antigos' devido à sua maior sofisticação, complexidade e integração. Torna-se necessário, portanto, um aumento do output da planta para fazer frente ao alto custo dos equipamentos flexíveis. Poderiase argumentar que a maior divisibilidade destes equipamentos permitiria a aquisição destes com capacidade menor. Acontece que essa maior divisibilidade na verdade só é verificada em produtos 
baseados em semicondutores como computadores, não em equipamentos de produção. Além do mais, as economias de escala continuam importantes, uma vez que os custos dos equipamentos aumentam em proporção menor do que a sua capacidade. Por fim, computadores e ferramentas podem ser compartilhados entre vários equipamentos, possibilitando à planta com maior número de equipamentos um custo unitário menor (ibid).

Logicamente, as novas tecnologias propiciam cortes diversos nos custos. Os custos com a mão-de-obra diminuem substancialmente devido à própria natureza racionalizadora da tecnologia com base microeletrônica. Entretanto, esta redução nos custos, em termos percentuais, é menor do que a redução do número de postos de trabalho, uma vez que a mão-de-obra que permanece deve ser mais qualificada e portanto, bem paga.

Os custos com matérias-primas também diminuem, devido à maior eficiência no processo de produção. $\mathrm{O}$ desperdício é minimizado, o material é utilizado mais racionalmente e menos produtos são rejeitados devido à má qualidade. Os custos com estoques também são cortados.

O problema é que, apesar da maior taxa de utilização do maquinário flexível, os custos totais de capital são tão altos que prevalecem sobre as outras reduções de custos (para um mesmo nível de output da produção com as 'velhas' tecnologias) (ibid). Uma máquina-ferramenta $\mathrm{CNC}$ custa de 50 a $100 \%$ a mais, em média, do que a máquina convencional que a mesma substitui. O custo de um FMS substituindo linhas trânsfer e produzindo com o mesmo output anterior foi $25 \%$ maior numa fábrica de freios, $200 \%$ maior numa planta de velocímetros e 4 a 5 vezes mais alto em fábricas de compressores e arcondicionados.

ALCORTA (1994) apresenta alguns dados de escala de produção para mostrar que realmente ocorre um 'scale-up' em diversos setores onde as novas tecnologias possuem maior penetração. Se na década de 1970 a produção ótima na indústria automobilistica era de aproximadamente 250.000 unidades, as novas plantas atuais também produzem de 250.000 a 300.000 carros, apesar da tendência apontar sempre para a diluição da produção total em maior número de modelos. O fenômeno de 'scaling-up' também é verificado na indústria de bicicletas e nas firmas relativamente pequenas de eletrônica, maquinários e instrumentação industrial, além das indústrias de processos, como siderúrgica e papel e celulose. No entanto, o autor lembra o potencial estratégico destas novas tecnologias, uma vez que permitem às grandes firmas competir em nichos de mercados antes exclusivos das pequenas, com produtos diferenciados e preços atraentes.

Em suma, as novas tecnologias são mais rápidas, eficientes e confiáveis e podem operar por mais longas horas, 


\section{PRODUÇÃO}

resultando na expansão da capacidade. Por meio da redução dos tempos de 'setup' e aumento da variedade, essas novas tecnologias conferem uma expansão ainda maior da capacidade: assim, as economias de escopo reforçam as economias de escala a nível de planta.

Se for tomado como objeto de análise a firma como um todo, também verificase um aumento nos custos fixos, o que obriga um aumento de escala para a sua amortização.

Em termos de P \& D, apesar de ser difícil fazer uma correlação entre aumento nos custos e novas tecnologias, alguns fatores podem proporcionar uma subida nos custos. Em primeiro lugar, essas tecnologias requerem uma certa quantidade de conhecimento acumulado em várias disciplinas e a sua integração. Além disso, os novos produtos, em particular os que se situam na 'fronteira tecnológica', são fortemente baseados na ciência e resultam de um longo processo de experimentação, e seu desenvolvimento implica em numerosas novas tarefas e um tempo extenso. Outrossim, sendo os produtos mais complexos tecnicamente, o seu desenvolvimento torna-se ainda mais difícil. A adaptação da tecnologia de produto aos novos equipamentos também requer um esforço adicional de $P$ $\&$ D. Identifica-se também a redução do ciclo de vida dos produtos - resultante, entre outros fatores, do aumento da velocidade de manufatura e maior flexibilidade - com o aumento dos custos de desenvolvimento destes, devido à necessidade de desenvolver mais produtos para evitar a sub-utilização da capacidade e manter a firma competitiva. Por fim, as novas tecnologias criaram demanda para novas tecnologias de processo: os FMS, por exemplo, implicam em pesquisas em organização da produção e pré-instalação. ALCORTA (1994) apresenta dados que mostram um aumento de gastos em P \& $\mathrm{D}$ em vários paises e setores, como automobilístico, eletrônica e máquinasferramentas.

Em termos de marketing, os custos aumentam devido à maior variedade de produtos e à intensividade de informação nas vendas.

Esses aspectos citados conferem uma outra visão a determinadas conclusões encontradas na literatura. $\dot{E}$ comum, por exemplo, deparar-se com determinados modelos de pequenas firmas empregando as novas tecnologias flexíveis, produzindo em pequena escala e explorando pequenos mercados como sendo uma alternativa para os países em desenvolvimento (PEREZ, 1985). Como foi visto, isso está muito distante da realidade, pelas próprias características e implicações destas tecnologias. Como observa ALCORTA (1994), as plantas ainda precisam produzir 250.000 carros ou 500.000 televisores para serem eficientes. Os paises em desenvolvimento que não tiverem condições de propiciar este nível agregado de demanda não poderão produzir com eficiência. $O$ autor conclui que a barreira imposta pela necessidade de obtenção de economias de escala para entrar no mercado continua existindo. 
Por outro lado, a possibilidade de redução de escala a nivel de produtos propicia novas oportunidades para produzir para uma série de nichos de mercado diferenciados.

\section{Considerações Finais}

De tudo o que foi dito acima a respeito das características e implicações das economias de escala e de escopo e da transição das estruturas de produção de um modelo baseado nas primeiras para outro calcado nas segundas, a conclusão mais importante possui um caráter esclarecedor e desmistificador.

As economias de escopo, como foi observado acima, são economias de escala. Mas, ao invés de se referirem a um só bem, se referem a um conjunto destes. $O$ conceito não é novo, e não se relaciona diretamente com as tecnologias de base microeletrônica: estas, sim, conferiram uma nova dimensão às economias de escopo, ampliando a viabilidade de sua utilização.

Com a identificação do conceito de economias de escopo com o de economias de escala e as observações feitas em relação aos custos das novas tecnologias e o seu efeito de 'scaling-up' na produção das firmas, restringe-se ao extremo a amplitude setorial da difusão do conceito. Elimina-se, de início, a idéia de pequenas firmas usufruindo economias de escopo.

Isto, de fato, não chega a ser tão surpreendente quando se considera as complexas questões a serem enfrentadas na produção de maiores variedades, tais como: os altos custos de capital; os problemas técnicos que se apresentam quando a automação flexível começa a ser empregada; a necessidade de avançados conhecimentos e práticas de integração, gerenciamento e manutenção do aparato tecnológico.

Se forem realmente levados em consideração apenas os setores que vêem possibilitados os investimentos nas novas tecnologias, fica-se com as indústrias que têm escala de produção: isto é, precisamente as indústrias que exploravam as economias de escala no paradigma Fordista de produção em massa.

Concluindo, as economias de escopo beneficiam justamente os setores que se beneficiaram - e se beneficiam - com as economias de escala.

\section{Referências Bibliográficas}

ALCORTA, Ludovico. The impact of new technologies on scale in manufacturing industries: issues and evidence. World Development. Inglaterra, v. 22 , no 5, p. 755-769, 1994.

CAIRNCROSS, Sir Alec. Introduction to Economics. 5a edição. Londres, Butterworths, 1973.

ChANDLER, Jr., Alfred D. Scale and Scope: The Dynamics of Industrial Capitalism. EUA, Belknap / Harvard, 1990. 


\section{PRODUÇÃO}

HAYES, R.H E WHEELWRIGHT, S.C. Restoring our Competitive Edge: Competing through Manufacturing. New York, Wiley, 1984.

KRAJEWSKI, L.J. e RITZMAN, L.P. Operations Management: Strategy and Analysis. $4^{\mathrm{a}}$ ed. EUA, AddisonWesley, 1996.

PEREZ, Carlota. Microelectronics, long waves and structural change: new perspectives for developing countries. World Development. Inglaterra, v. 13, no 3, pp. 441-463, 1985.

PINDYCK, Robert S. e Fordismo e Seus Desdobramentos na RUBINFELD, Daniel L. Organização da Produção: Um Estudo Microeconomics. 2a ed. EUA, Macmillan, Exploratório. Dissertação de mestrado. 1992.
POSSAS, Maria Silvia. Concorrência e Competitividade: Notas Sobre Estratégia e Dinâmica Seletiva na Economia Capitalista. Tese de doutorado. UNICAMP, 1993.

SCHERER, F. M. Industrial Market Structure and Economic Performance. 2a ed. EUA, Houghton Mifflin, 1980.

SHINGO, S. O Sistema Toyota de Produção do Ponto de Vista da Engenharia de Produção. Porto Alegre, Bookman, 1996. PUC-Rio, 1995. 